\title{
Inflammatory mediators of neuropathic pain
}

\author{
Mediadores inflamatórios na dor neuropática \\ José Oswaldo de Oliveira Júnior ${ }^{1}$, Caio Sander Andrade Portella Junior² ${ }^{2}$ Cláudia Panossian Cohen ${ }^{3}$
}

DOI 10.5935/1806-0013.20160045

\section{ABSTRACT}

BACKGROUND AND OBJECTIVES: Pro-inflammatory chemical mediators and algogenic substances seem to be confused by the sharing of their actions and by interactions in painful and inflammatory presentation. This study aimed at presenting a review of major inflammatory chemical mediators and place them in neuropathic pain pathophysiology.

CONTENTS: Inflammation is the homeostatic response of vascularized tissues to remove harmful agents and restore their normal functions. Nervous system (central and/or peripheral) diseases and injuries may induce neuropathic pain and may also modify inflammatory process nervous mediation. In such pathological conditions, there might be pain without restrict link with admitedly harmful or painful stimuli, as well as there might be inflammation without restrict link with the presence of harmful agents and the need to remove them. Chemical mediators involved in neuropathic pain and inflammation pathophysiology modulate the presentation of both.

CONCLUSION: Studies on inflammation offer evidences to support the important role of their chemical mediators in neuropathic pain pathogenesis. In peripheral and central sensitization, a thin borderline between reversibility or not of neuropathic pain may be respected or exceeded by inflammatory mediators actions. Keywords: Adenosine triphosphate, Bradykinin, Chemical mediators, Chemokines, Citokines, Eicosanoids, Histamine, Inflammation, Neuropathic pain, Neurotrophic factors.

\section{RESUMO}

JUSTIFICATIVA E OBJETIVOS: Mediadores químicos pró-inflamatórios e substâncias algogênicas parecem se confundir pelo compartilhamento de suas açóes e pelas interaçóes no quadro doloroso e inflamatório. O objetivo deste estudo foi apresentar uma revisão sobre os principais mediadores químicos inflamatórios e situá-los na fisiopatologia da dor neuropática.

CONTEÚDO: A inflamação é a resposta homeostática de tecidos vascularizados no sentido de remoção de agentes lesivos e restauro de suas funções normais. Doenças e lesóes no sistema nervoso (central e/ou periférico) podem causar dor neuropática, e, também modificar a mediação nervosa do processo inflamatório. Nessas condiçôes patológicas a dor pode ocorrer sem o vínculo restrito com estímulo reconhecidamente nocivo ou doloroso, assim como ocorrer quadro inflamatório sem o vínculo restrito com a presença de agentes lesivos e a necessidade de removê-los. Os mediadores químicos envolvidos na fisiopatologia da dor neuropática e da inflamação modulam o quadro de ambas.

CONCLUSÁO: Os estudos sobre inflamação oferecem evidências para embasar a importância do papel dos seus mediadores químicos na patogênese da dor neuropática. Na sensibilização periférica e, também na central uma fronteira tênue entre a reversibilidade ou não do quadro neuropático pode ser respeitada ou ultrapassada pelas açóes de mediadores inflamatórios.

Descritores: Bradicicina, Citocina, Dor neuropática, Eicosanóides, Fatores neurotróficos, Histamina, Inflamação, Mediadores químicos, Quimiocinas, Trifosfato de adenosina.

1. Fundaçăo Antônio Prudente, Escola de Cancerologia Celestino Bourroul, Departamento de Terapia Antálgica, Cirurgia Funcional e Cuidados Paliativos, São Paulo, SP, Brasil.

2. Hospital Deputado Luis Eduardo Magalhāes, Serviço de Neurocirurgia. Porto Seguro, BA. Brasil.

3. Hospital Alemáo Oswaldo Cruz, Grupo de Dor, Sảo Paulo, SP. Brasil.

Conflict of interests: none - Sponsoring sources: none.

\section{Correspondence to:}

José Oswaldo de Oliveira Júnior

Rua Pedroso Alvarenga, 1062, conjunto 55, 5andar

04531-004 São Paulo, SP, Brasil.

E-mail: jo.oliveirajr@yahoo.com.br

(c) Sociedade Brasileira para o Estudo da Dor

\section{INTRODUCTION}

Inflammation is a homeostatic response of vascularized tissues to remove noxious agents and restore their normal functions ${ }^{1}$. Nervous system (central and/or peripheral) (CNS, PNS) diseases and injuries may induce neuropathic pain (NP) and also change nervous inflammatory process mediation. In such pathologic conditions, pain may appear without strict link with noxius or painful stimuli, as well as there may be inflammation without strick link with the presence of noxious agents and the need to remove them.

$\mathrm{NP}$ is fruit of imperfect regeneration of PNS and/or $\mathrm{CNS}^{2}$. Inflammation is critical part of the attempt to restore tissue/cell and may be modulated by an intact or defective nervous system. Original cause of inflammation itself may or not be the same as that of NP and interaction of inflammatory and neuropathic processes shall inexorably occur.

According to its resolution time, inflammation may be acute or chronic. In acute inflammation, vascular changes result from the build up of fluids and polymorphonuclear cells at injury site. Migration of blood figured elements seems to be oriented by concentration of prostaglandins which would change the affinity of external chains of adhesion molecules receptors. Acute inflammatory responses may be systemic and include hyperthermia, leukocytosis, protein catabolism and liver plasma proteins synthesis, such as $\mathrm{C}$-reactive proteins ${ }^{1}$. Chronic inflammation has as characteristics cell infiltrate (lymphocyte and macrophage) and the simultaneous presence of injury and repair.

Pain is part of the first four classic signs of inflammation, together with blush, tumor and heat. Currently, they are recognized as elicited by a series of chemically mediated events, such as local vascular flow and patency changes, leukocytes infiltrate and algogenic substances release ${ }^{3}$.

Most of the times, these phenomena lead to process resolution; however, in cases where inflammation evolves to chronicity, there might be tissue destruction and the appearance of the fifth and most deleterious inflammatory signal: function loss ${ }^{3}$.

The inflammatory process is multimediated and sometimes even stereotyped, but it may show different responses as a function of noxious agent nature, of the predominant cell type of some infiltrates and of the participation of different chemical mediators ${ }^{3}$.

\section{PAIN AND SENSITIZATION}

In general, pain is an unpleasant perception and a nociceptive sensation. Pain is not an isolated event, but rather a sucession of linear and nonlinear events, which leads to a state of defensive hyperactivity, increasing the chance of detecting new styles and optimizing the defense system ${ }^{4}$.

Pain is a symptom, a complaint. There is pain if there is its complaint. It is undoubtedly a verbal manifestation and in a broader sense corporal. Its study should not allow a dissociation from biological, cultural and psychic factors; however, changes caused by the two latter are noticeable not only in the central nervous system ${ }^{4}$.

Sensitization to pain and inflammation in the periphery and in the peripheral nervous system

In periphery, substances released during tissue injury, which normally are found in relevant concentrations just inside the cells, act as sensitizers of peripheral painful receptors. Active receptors become hyperactive, while the so called silent receptors become active. There is global decrease in nociceptors thresholds $s^{4}$ Substances released to the intestitium are called algogenic and osmotically spread to neighbor areas. In passive osmotic diffusion the effects of active substances are proportional as they move away from the initial fulcrum.

Algogenic substances are called pro-inflammatory because they are able to 
promote vascular patency dilatation and alteration, they cause blush, heat and edema, in addition to helping the detection of potentially noxious stimuli.

Among algogenic substances there are $\mathrm{E}_{2}$ prostaglandins which, for their potency and interaction with other substances as from minimum concentrations, have peripheral sensitizing effect and trigger nociceptors centripetous or ortodromic action potentials $s^{4,5}$.

Cytolysis offers cell membranes for degradation, which is another source of pro-inflammatory and algogenic substances. Its metabolytes include prostaglandins and prostacyclins, leukotriens, tromboxanes, among others, which shall participate in the so-called "inflammatory soup" ${ }^{4-6}$.

Nociceptors receive painful impulses and, after translating them, transmit them to the second sensory neuron located in the gray matter posterior horn.

Nociceptors interact with the medium when they are excited, producing and releasing special algogenic substances (pro-inflammatory), such as A and $\mathrm{B}$ tachykinins and substance $\mathrm{P}$, a polypeptide related to calcitonin and somatostatin gene. These substances released in the interstitium are also spread by osmosis and act at a distance like other algogenic and anti-inflammatory substances, also decreasing nociceptors thresholds. They also act on neighbor cells making them degranulate and release pro-inflammatory and algogenic substances. Secreting function of nociceptors is proof of the neurogenic inflammatory action ${ }^{4,6}$.

Painful receptors have also their own receptors, such as those detecting the presence of proteolytic enzymes, especially triptases. Triptase receptors stimulation has a potent effect on the increased production of pro-inflammatory and algiogenic agents by nociceptoresl

\section{Sensitization to pain and central nervous system inflammation}

Central sensitization involves increased individual neuronal function (cellular) and of nociceptive circuits (multicellular, neuronal and glial) caused by increased membrane excitability and synaptic efficacy and also by decreased somatosensory nervous system inhibition and plasticity in response to peripheral inflammation, abnormal activity or nervous injury. It occurs after intense or repetitive nociceptive stimulus ${ }^{4}$.

In the absence of tissue injury or after its repair and healing, the alert state of decreased pain threshold and inflammation gradually returns along time to its less activated initial state. The system may return to a super-alert state in conditions when the risk of a new injury is high, such as in case of detection of new intense, repeated and persistent nociceptive stimuli.

Such sensitization is expression of synaptic plasticity occurring in CNS system and triggered by persistent nociceptive stimuli.

Chronicity may have a persistent facilitation, potentiation, increase and/ or amplification state. Injuries and diseases affecting the nervous system, especially the somatosensory system, may also create similar environments with different results. There is decrease in inhibitory influences of spinal cord dorsal horn gray matter and synaptic and intracelllular changes which peak with the permanent production of signalling of the presence of painful stimuli in the pathway, even in the absence of true peripheral stimulation, that is, spontaneously.

Second order nociceptive neurons, which have dynamic and adjustable behavior depending on their sensitization level, enable previously silent synapses which transmit non-painful stimuli (allodynia) and also others which conduct stimuli originating from other body areas outside the territory represented by spinal segment where they are located (referred pain). These wide dynamic range neurons (WDR) are considered convergence units and are recruited during central sensitization, even in the maintenance of nervous system integrity ${ }^{3,4}$.

In neuropathic situations related to injuries or diseases, biochemical scenarios may create shortcuts which abbreviate and decrease the set of stages observed in chronicity.

Situations of neuronal hyperactivity by somatosensory system impairment may generate neuropathic pain and, sometimes, simultaneously with inflammation. Resulting NP is largerly created and sustained by inflammatory process cascade.

\section{General scenario}

Diffuse inflammatory mediators are released both by infiltrative and resident immune system cells and by glial cells with immune function, which activate or sensitize nociceptors, thus leading to an aberrant nociceptive system activity. Chemical pro-inflammatory mediators may act on neighbor glial cells, or lead to increased migration of immune system cells, inducing distant release of more mediators ${ }^{6}$.

Changes are detected both in CSN and CSP and the interaction with which pain transmission pathway components create conditions for nervous system injuries, mimiking excitoxicity shown in other aggression situations. Neurogenic inflammatory changes identified in the periphery, close to nociceptor terminations, in conditions of nervous system preservation, are also observed in dorsal root ganglion, dorsal region of spinal gray matter and in some brain areas associated to pain, after peripheral nervous injur $y^{4}$. Painful phenomenon comprises a long and increasing list of inflammatory mediators including bradykinin, eicosanoids (prostaglandins and leukotriens), adenosine triphosphate (ATP), histamin, pro-inflammatory cytokines (tumor necrosis factor, TNF, interleukin-1b and IFNy), chemokines (chemotactic cytokine ligant 2, CCL2; fractalkine), neurotrophins (nerve growth factor, NGF; brain neurotrophic factor, BDNF) and oxygen reactive species ${ }^{6,7}$.

Building a biochemical trend of balance, many mediators such as immune cell-derived endorphins, anti-inflammatory cytokines (IL-10 and TGFB) and some neurotrophic factors (glial neurotrophic factor, GNF), show opposite effects to pain mediators ${ }^{8}$.

\section{General concept}

Inflammatory chemical mediators are substances released in injured tissue or by adequately activated cells which coordinate the inflammatory response process. These are major determinants of the sequence of injured or ill nervous system neuroinflammation, and are major contributors to NP.

DETAILS OF MAJOR INFLAMMATORY MEDIATORS INVOLVED WITH PAIN

\section{Bradykinins}

Bradykinin is a nonapeptide (peptide formed by nine aminoacids) of low molecular weight, from the vasoactive kinins family with short plasma halflife and low blood circulation levels.

Bradykinins biological activity is mediated by two receptor pathways, called B1 (B1R) and B2 (B2R) receptors ${ }^{7}$. Bradykinin activation of both receptors induces inflammation via pro-inflammatory cytokines release and increased vascular patency.

Bradykinin B2 receptor is constitutively expressed by peripheral and central tissues, while $\mathrm{B} 1$ receptor is induced and regulated according to the evolution of infection, inflammation or trauma. In the nervous system, for example, B2 receptor is found, in normal situations, in different types of cells, including sensory neurons and microglial cells, while B1 receptor is sensitized in microglial cells, astrocytes and neurons after tissue injury?. NP studies in animal models have shown that both bradykinin receptors play a hypersensitization role in pain. B2 alone contributes for the acute inflammatory and nociceptive response phase, while both (B1 and B2) are important for the central NP process and transition to chronic pain ${ }^{9,10}$.

Bradykinins contribute to NP by sensitizing peripheral nociceptors terminals and potentiate spinal cord glutamaergic synaptic transmission ${ }^{11}$. They also contribute to perpetuate cytokines and chemokines inflammatory cascade, as well as to stimulate histamin release by mast cells $s^{6,7}$.

Experimental intraplantar injections of B1 or B2 receptor agonists increase response to pain $^{12}$, while antagonists injection inhibits hyperalgesia in NP models ${ }^{13}$

Decreased hyperalgesia secondary to nervous injury obtained by deleting the gene responsible for $\mathrm{B} 1$ receptors in mice confirms the important role of bradykinin as central inflammatory mediator in $\mathrm{NP}^{14,15}$.

\section{Adenosine triphosphate}

The complex panel of purinergic systems and their importance in several pathophysiologic mechanisms is just recently emerging and generating scientific interest. The scientific community has resisted a long time until admitting that such a common metabolyte as ATP could have actions going beyond its known participation in energetic metabolism ${ }^{16}$.

In fact, ATP is a multifunctional molecule also involved in signal transduction by cells. ATP, when released in the extracellular space after cell destruction, participates in the modulatory control of neuronal activity. Painful sensitivity mediation by the activation of ionotropic (P2X, ion channel) 
and metabotropic (G protein-bound P2X) membrane receptors ${ }^{17}$.

ATP may help pain transmission by some mechanisms: activation of $\mathrm{C} \mathrm{fi-}$ bers receptors causing increased axonal peripheral nerve sensitivity; activation of primary afferent pathway in spinal cord pre-synaptic terminal; and induction of pain mediators release such as BDNF and glial pro-inflammatory cytokines to activate and sensitize nociceptors ${ }^{6}$.

NP models in which the application of A-317491, P2X3 and P2X2/3 receptor antagonists or with treatment with oligonucleotide of reverse P2X3 sense, causes decrease in dorsal root ganglion protein expression (DRG) and spinal cord, which attenuates both thermal hyperalgesia and mechanical allodynia in rats with peripheral nerve injury, indicating action of $\mathrm{P} 2 \mathrm{X} 3$ receptor on NP.

$\mathrm{P} 2 \mathrm{X} 4, \mathrm{P} 2 \mathrm{X} 7$ and $\mathrm{P} 2 \mathrm{Y} 12$ receptors expressed in the microglia appear as having new and important role in NP etiology. Their activation by ATP is related to microglial response to peripheral nerve injury which contributes for the hyperexcitability of spinal dorsal gray matter and for NP symptoms. Spinal microglial activation is a major pathologic process, occurs less than four hours after peripheral nerve injury and is strongly correlated to proinflammatory cytokines release and hyperalgesia ${ }^{6}$.

Recent pharmacological, genetic and behavioral studies have shown that purinergic P2X 4 receptors are necessary and sufficient for NP. Their expression is increased in spinal microglial cells after nervous injury and spinal administration of these cells previously stimulated by ATP in animals induces allodynia similar to that caused by peripheral nerve injury ${ }^{18,19}$.

The mechanism by which P2X 4 microglial receptors stimulation produces NP involves phenotypic electrophysiologic changes in spinal cord dorsal horn lamina I neurons. The activation of these receptors promotes BDNF release, which causes dorsal horn neuronal disinhibition by interrupting homeostasis of intracellular chlorine ion ${ }^{20}$. P2X 4 may safely be considered a major mediator of neuron-microglia signalling and its blockade reverts hyperalgia.

The activation of $\mathrm{P} 2 \mathrm{X} 7$ receptors in immune cells (mast cells, macrophages, $\mathrm{T}$ lymphocytes and microglia) induces fast activation and secretion of interleukin $1 \beta$ (IL-1 $\beta)^{21}$. Rats treated with P2X7 antagonist show decreased hypersensitivity to pain, while sensitization of $\mathrm{P} 2 \mathrm{X} 7$ receptors is detected in DRG and in peripheral nerves of NP patients ${ }^{22}$. The variation of genetic sequence coding P2X7 receptors affects the formation of pores, promoting sensitivity to chronic pain both in rats and in humans, indicating the possibility of a new strategy to control chronic pain ${ }^{23}$.

P2Y12 receptors also activate microglia and contribute to NP. The activation of these receptors promotes the involvement of microglial cells with myelinated axons in spinal dorsal gray matter ${ }^{24}$. The inhibition of these same receptors by P2X12 antagonists or genetic deletion of gene P2ry12 relieves hyperalgesia in animal NP models ${ }^{25}$. The P2X12 receptor antagonist, clopidogrel, is clinically used to prevent the formation of blood clots, which may speed the screening of therapeutic agents in NP. So, purinergic system is a promising set of therapeutic targets to control nociceptive and inflammatory NP processes.

\section{Eicosanoids}

Eicosanoids are a numerous family of compounds with high potency and broad biological activity spectrum. These are long-chain polyunsaturated fatty acids oxygenation products. One of these acids, the arachidonic acid, constituent of cell membranes, is the most abundant and important precursor of eicosanoids.

Cleavage (also known as release or mobilization) of cell membranes arachidonic acid, which makes this fatty acid of 20 carbons amenable to be oxygenated. Although cleavage may happen without cell death, it is in injury and degeneration that there is higher availability for the acid to be metabolized; and so, its metabolytes become indicators of noxious or potentially noxious stimuli $i^{4,6,7}$.

Arachidonic acid oxygenation is documented in four different pathways: that catalyzed by cyclo-oxygenases (COXs), that by lipoxygenase, that by epoxygenase and the isoprostane pathway.

After being cleaved from cell membrane by phospholipase $\mathrm{A}_{2}$, arachidonic acid may be converted into prostaglandins by cyclo-oxygenases (COXs) or into leukotriens (LTs) by lipoxygenases.

Products of endoperoxide synthase enzymes (cycloxygenases or COXs) COXs pathway consists of the action of at least two enzyme isoforms:
COX-1 and COX-2.

COX-1 is found in most tissues, promoting homeostasis (although its expression may be high after cell trauma); while COX-2, the expression of which at rest is low, is rapidly increased by the action of inflammatory mediators (cytokines) after injury.

Prostaglandins PGE2 and PGI2 are major COXs pathway products and are predominantly activated by PE receptors (PE1-4 to PGE2 and PI receptors to PGI2) ${ }^{4}$. These prostaglandins activate sensory afferent fibers and promote spinal cord nociception by depolarization of WDR-type neurons and block neuronal inhibition by glycin ${ }^{5,26,27}$.

COX-2 and PGE2 expressions drastically and slowly (months) increase after nervous injury both in injury site and spinal cord.

Non-selective COX, COX-2 inhibitors and PE1 antagonists locally or intrathecally, relieve hypersensitivity to pain in NP models.

Clinical observation repeated in animal models considers macrophages infiltration as major source of COX-2 after nervous injury and has shown that PE1 receptors expression in macrophages is also abnormally increased, suggesting a vicious inflammatory cycle ${ }^{6}$.

E2-type prostaglandin has been recently related to increased production of pro-inflammatory cytokines, IL-6 and neutrophic factors, BDNF, in DRG nervous injuries, in addition to contributing for the medium of pain mediators ${ }^{6,27}$.

In practice, the use of COXs inhibitors is innefective for NP, in spite of proven generalized action of such enzymes and their products (especially prostaglandins) in the development and maintenance of NP and the efficay of enzyme inhibitors (of COXs) to treat inflammatory pain. This seemingly paradox is still to be explained ${ }^{6,28}$.

\section{Lipoxygenase products}

Arachidonic acid metabolism is also catalysed by lipoxygenases (LOX): 5-, 12- and 15-lipoxygenase producing hydroperoxyeicosatetranoic acids (HPETE) which in turn are rapidly converted in hydoxy derivatives (HETE) and leukotriens ${ }^{6}$.

The interest on lipoxygenase pathway, also known as allergic inflammation pathway, is to better understand and improve the management of asthma, anaphylactic shock and cardiovascular disease.

Leukotriens (LTs) are a group of lipid chemical mediators formed by the insertion of oxygen in different positions inside arachidonic acid. 5-lipoxygenase (5-LOX), enzyme present in inflammatory cells (leucocytes, polymorphonuclear, basophils, mast cells, eosinophils and macrophages) catalyses LTA4 formation which, together with its metabolytes (LTB4, Ciseinil LTs or cisLTs, LTC4, LTD4 and LTE4) are the most widely studied ${ }^{6,29}$

The activation of these inflammatory cells induces increase in calcium free ions in respective cytoplasms and releases arachidonic acid for oxygenation by 5-LOX (in turn activated by its own activating protein 5-LOX FLAP) which produces an unstable intermediate epoxy-type substance, leukotrien A4 (LT4). At this point, epoxyde may be converted into dihydroxi leukotrien B4 (LTB4) or suffer conjugation with glutadione. In conjugation there is formation of leukotrien C4 (LTC4), which suffers the action of different peptidases in its recently conjugated portion (a true sequential degradation) forming LTD4 and LTE4. The latter products and C4 are called cisteinil leukotriens or pepetidoleukotriens.

LTs action on specific receptors for LT in the surface of many immune and glial cells; BLT1 is receptor with affinity for LTB4, while BLT2 has lower affinity for LTB 4 and other LTs; CisLT 1 and 2 are selective receptors ${ }^{29}$.

LTB4 exerts strong chemotaxis on neutrophyls expressing BLT (1 and 2). Intraplantar LTB injections produce hyperalgesia by inducing the release of other leukotriens ( $8 \mathrm{R}$ and 15S-diHETE), which sensitize nociceptors and may contribute for NP. The inhibition of 5-LO confirms the findings commented above and decreases hyperalgesia resulting from LTB4-induced NGF release $e^{4,6,7}$

Zafirlucaste, cisLTs antagonist, decreases pain hypersensitivity in inflammatory pain models ${ }^{29}$.

In models of peripheral nerve injury-induced NP, there are activated spinal microglial populations. Recent studies have shown that these microglial cells have increased expression of 5-LO and cisLT1s, together with increased BLT1 receptors ${ }^{30}$.

Closing the set of evidences on the role of such inflammatory chemical mediators on NP, intrathecal application of 5-LO inhibitors (BLT1 antago- 
nists) causes microglia inactivation. When added to inhibitors of protein kinase activated by mitogen p38 (MAPK), they are able to revert mechanical sensitivity ${ }^{30}$

Agents developed to block leukotriens synthesis (zileuton) and signalling (motelucaste, zafirlucaste and pranlucaste) show clinic therapeutic success to treat inflammatory diseases such as asthma, but their efficacy to treat NP is still not scientifically proved.

\section{Histamine}

Histamine is a biogenic endogenous ammine which mediates pleiotrophic effects by means of four different subtypes of receptors bound to $G$ proteins, called $\mathrm{H} 1$ to $\mathrm{H} 4$, which are expressed in different manners in each cell type.

In humans, histamine is a major mediator of immediate and inflammatory allergic reactions, although playing a modest role in anaphylaxis. With complex physiologic and pathologic effects causing broad effects, part of them undesirable, histamine has never been adopted as drug to treat diseases, giving place to selective agonists or antagonists of some subtypes of its receptors.

Classic source of histamines are mast cells, where they are stored in cytosolic granules and released by exocytosis to exert several actions is response to different simuli. Histamine not coming from mast cells derives from multiple sources, such as circulating leucocytes (especially eosinophyls, althoug in concentrations ten times lower) and neurons. Gastric cells producing histamine are called histaminocytes and in the central nervous system they are called histaminergic neurons. It is believed that mast cells degranulation in the nervous system is triggered by tissue injury or by increased adenosine or bradykinin in response to mechanical injury ${ }^{6,7}$.

Immune processes are the most important mechanism of histamine release by mast cells and basophils. These cells, when sensitized by $\operatorname{IgE}$ antibodies fixed to its surface, respond to antigens with histamine and/or other mediators release (by citolysis or exocytosis).

Once released, histamine is able to sensitize nociceptors resulting in hyperalgia. Treatment with mast cells stabilizer chromolyn, prevents the development of hyperalgia, partially secondary effect of lower histamine release $^{31}$. Local treatment of injured nerve with $\mathrm{H} 1$ and $\mathrm{H} 2$ receptor antagonists relieves hyperalgesia. Mild analgesia of anti-histaminics is clinically shown in dysmenorrhea, trigeminal neuralgia, thalamic pain syndrome and cancer pain, although being in general associated to opioids ${ }^{8}$. A new generation of anti-histaminics acting on $\mathrm{H} 3$ and $\mathrm{H} 4$ receptors is being currently tested in NP, producing conflicting results. Peripheral and spinal activation of $\mathrm{H} 3$ receptors inhibits formalin-induced nociception $^{32}$. Systemic administration of $\mathrm{H} 3$ receptors antagonists decreases mechanical sensitivity in experimental NP models $s^{33}$. In spite of the poor knowledge on the antinociception mechanism of anti-H3, they are already being clinically tested. Effects on $\mathrm{H} 4$ receptors block in NP models are also still not clear. A study has shown that treatment with $\mathrm{H} 4$ agonists blocks mechanical sensitivity, while others have shown that systemic use of $\mathrm{H} 4$ antagonists has dose-dependent and reversible effect on mechanical hypersensitivity ${ }^{33}$.

Histamine effect on NP is clearly shown, however further studies are needed before considering the use of selective histamine agonists/antagonists to manage $\mathrm{NP}^{6}$.

\section{Neurotrophic factors}

Neurotrophic factors are a family of proteins of central importance to nervous system functioning, differentiation and survival, as well as synaptogenesis and synaptic plasticity.

Neuronal growth factor is member of the neurotrophins super-family (NT), which includes BDNF, NT-3 and NT-4/5.

Nerve growth factor (NGF) is one of the most widely studied neurotrophins and regulates survival, development and trophism of specific neuronal populations, being recognized as one of the most important pain mediators. Increased levels of NGF are seen after nervous injury in animal models ${ }^{34}$ and in different critical situations involving pain, such as arthritis and chronic headache.

Nerve growth factor release promotes peripheral sensitization in different manners, such as by modulating the expression of other inflammatory mediators, receptors and ionophors.
Its administration in control animals and previously healthy humans induces fast hyperalgia ${ }^{35}$. In experimental models with nerve injury, the administration of anti-NGF neutralizes antibodies with complete reversion of hypersensitivity and hyperalgia ${ }^{36}$.

Monoclonal antibodies targetting NGF have been involved in different studies. One example is tanezumab, monoclonal anti-NGF antibody tested for different types of pain, including knee osteoarthritis and chronic low back pain. Results of pain control are promising, being more effective than non-steroid anti-inflammatory drugs, however many patients had adverse effects such as changes in peripheral sensitivity, in addition to progressive worsening of osteoarthritis with bone necrosis ${ }^{37}$.

NGF has major effect on tissue repair, on angiogenesis and cell proliferation, thus questions about the benefits of anti-NGF therapies to control chronic pain ${ }^{38}$. On the other hand, there is currently a broad range of anti-NGF being tested, and it is premature to conclude something about its application to treat chronic pain which always incorporates neuropathic mechanisms.

Brain-derived neurotrophic factor (BDNF) is considered a pro-nociceptive neurotrophin since the demonstration of its ability to signal for microglia and spinal cord neurons, mediating aberrant pain.

Peripheral nerve injury causes activation of spinal microglia P2X4 receptors. The production of adenosine triphosphate (ATP) induced by the activation of these receptors leads to cell inflow of free calcium ions, which in turn induces secondary phosphorylation and activation of mitogenactivated protein kinase $38 \mathrm{kDa}$ (p38MAPK) which subsequently leads to increased BDNF exocytosis dependent on increase and sensitization of soluble $\mathrm{N}$-ethylmaleimide-sensitive factor attachment protein receptor (SNARE).

BDNF release by activated microglial cells induces disinhibition of second order nociceptive neurons present in Rexed lamina I of spinal cord gray matter when breaking intracellular chlorine homeostasis. Modification induced by BDNF release transforms local neurons function, before predominantly inhibitory (or GABAergic), and one third of neurons start to have excitatory action ${ }^{39}$.

Two BDNF release pathways in NP were recently described. The first is triptase-dependent (proteolytic enzyme) and mast cells-derived, which activates proteinase activated receptor type 2 (PAR2) and promotes the expression of $\mathrm{P} 2 \mathrm{X}$ in microglial cells on which ATP exposure significantly increases BDNF synthesis and activity ${ }^{6}$.

Approximately fifteen years ago, PAR2 inhibitors were considered the new analgesics of the $21^{\text {th }}$ Century, but such receptors found in peripheral nociceptive receptor surface are the most potent inducers of peripheral algogenic substances release (pro-inflammatory chemical mediators) responsible for neurogenic inflammation.

In posterior spinal cord gray matter, the biochemical scenario is repeated and the same substances or mediators are found, in addition to excitatory aminoacids. However, the study of those then promising analgesics has not progressed due to adverse effects caused by the same receptors located in different $\operatorname{sites}^{40}$. In the second pathway, BDNF is released in the trigeminal ganglion by activity-dependent TNF pathway ${ }^{6,41}$.

Findings explain the different forms by which BNDF may be inhibited, but strategies to control NP are still to be investigated.

GDNF produced by astrocytes and glial cells has antinociceptive action on central nervous system in spite of the pro-nociceptive action in the peripheral system ${ }^{8}$. Spinal treatment with GDNF reverts NP by means of increasing somatostatin expression, which is a neuropeptide with analgesic properties ${ }^{42}$.

Another mechanism of spinal GNDF antinociceptive potential is by means of decreased astrocytes activation in spinal cord posterior horn after nervous injury ${ }^{43}$, however, clinical trials with recombinant GNDF in Parkinson's disease patients were discontinued due to adverse effects.

\section{Citokines and chemokines}

Citokines are small regulatory proteins produced by a wide variety of cells, including leucocytes, under physiologic and pathologic conditions. They modulate cell-to-cell interaction in addition to regulating local inflammatory and immune responses.

Chemokines are a large family of structurally homologous cytokines with chemotaxis capacity, which orient migration of leucocytes to the injury site. Chemokines, other cytokines and their receptors are broadly ex- 
pressed in the central nervous system and there are increasing evidences of their action on NP.

There are many inflammatory cytokines involved in NP models, such as IL-1 $\beta$, TNF, IL-6, IL-15, IL-17, IL-18 and INF- $\gamma$, while anti-inflammatory cytokines, such as IL-4, IL-10 and TGF- $\beta$ have analgesic action. Immune homeostasis is normally maintained by endogenous anti-inflammatory cytokines release, particularly IL-10, which makes negative feedback when suppressing genes coding pro-inflammatory cytokines and their receptors. However, if the central nervous system is injured, there is release of IL-1 $\beta$, TNF and IL- 6 and there is positive feedback to activate inflammatory cascades.

Many pro-inflammatory cytokines indirectly contribute to pain due to their ability to potentiate the production of algiogenic mediators such as PGE- 24 . Interaction is narrowed when the effect on the affinity state of external anchorage of adhesion molecules of blood figured elements are studied $^{45}$. There is strong evidence of the direct action of some cytokines on receptors present in nociceptors.

Cytokines, including chemokines released after nervous injury, may modulate spinal blood-spinal cord barrier patency by increasing IL-1 $\beta$ and CCL2 circulation ${ }^{46}$. Spinal infiltration of immune cells is related to cytokines release.

The balance between pro and anti-inflammatory cytokines after nervous system injury is essential both for its own recovery and the development of NP. Patients with complex regional pain syndrome, painful neuropathy and spinal injury have systemic increase of TNF and IL-6 pro-inflammatory cytokines release, in addition to levels of anti-inflammatory cytokines such as IL-10 and IL-4, while those with painless neuropathy have increased levels of anti-inflammatory cytokines ${ }^{6}$.

Cytokines modulation when blocking pro-inflammatory cytokines and/ or increasing anti-inflammatory cytokines is effective to control pain and brings to light the discussion about the effects of cytokines on NP.

\section{Pro-inflammatory cytokines}

\section{Tumor necrosis factor}

Tumor necrosis factor (TNF) is probaly the most widely studied proinflammatory cytokine and acts by two receptors: constantly expressed TNFR1 and inducible TNFR2.

TNF starts several signalling pathways: activates nuclear factor (NF)-KB, which induces transcription of pro-inflammatory cytokine coded genes, thus triggering an inflammatory cascade ${ }^{47}$.

Several animal studies confirm the role of TNFs in neuropathic pain, however, actions of TNFR1 and TNFR2 receptors are still not totally explained. Behavioral, pharmacological, and electrophysiologic studies confirm the significant contribution of TNF to peripheral and central nervous system sensitization.

When TNF is applied to healthy sciatic nerve and DRG (dorsal root ganglion) there are ectopic firings of $A \delta, A \beta$ and $C$ fibers, thus decreasing mechanical threshold needed to activate $C$ fibers ${ }^{8}$. After nervous system injury, endogenousTNFs are launched by mast and Schwann cells, which are followed by a second wave of TNFs launched by netrophylic infiltrates amd macrophages ${ }^{8}$. Elevation of TNFs is correlated to pain and hypersensitivity.

TNF increases vascular patency in hairless skin increasing leucocytes infiltration and consequently inflammatory response. These effects support the theory which suggests that TNFs are peripheral sensitizers. Nervous injuries also trigger increased TNF in spinal cord dorsal part, which increases NAV 1.3 and NAV 1.8 sodium channels expression ${ }^{53}$, as well as increases post-synaptic excitatory chain by means of AMPA and NMDA receptors ${ }^{49}$, both susceptible to central sensitization.

The interference of TNF signalling using neutralizing antibodies or antagonists of their receptors may attenuate $\mathrm{NP}^{8}$. In the last decade, treatment with anti-TNF (infliximab, etanercept) has positively transformed the treatment of severe inflammatory diseases, such as rheumatoid arthritis, inflammatory bowel diseases and psoriasis. These drugs are effective to revert hyperalgesia in painful rat models and in rats with neuropathic pain due to nervous injury ${ }^{52}$.

Interleukin-1

Intereleukin-1b is the second more important pro-inflammatory cytokine which, when applied to healthy nerves, dorsal roots ganglia and dorsal spine decrease activation threshold and promote spontaneous firings of action potential, thus causing pain and hypersensitivity ${ }^{6,8}$. Close to a peripheral nervous injury, IL-1b is rapidly released by Schwann cells, as well as by local macrophages and infiltrates.

In spinal cord, nervous injury activates microglial and astocytary cells and this activation results in a 15-fold increase in the levels of IL-1b, effect totally reverted with glial inhibitor propentophilin, which also normalizes pain and hypersensitivity ${ }^{53}$.

Pain worsening mechanism of IL-1b includes: reinforcement of voltagedependent sodium chains in painful receptors by "p38 pathway"; increased excitatory chains by means of NMDA and AMPA receptors phosphorylation; and spontaneous decrease of GABA and current-inhibiting glycin on spinal cord ${ }^{49}$.

There is analgesic effectiveness on IL-1 receptors block or interfering with IL-1b signalling via neutralizing antibodies in NP models ${ }^{8}$.

IL-1 antagonist anakinra was clinically approved for rheumatoid arthritis and may be also beneficial for NP patients.

A recent study ${ }^{54}$ has stressed IL-1b potential on nervous regeneration since it has been shown that IL-1b in rats elicits evident losses in injured nerve function recovery. The therapeutic possibility comes from the probable benefit of blocking such interleukin.

\section{Interleukin-6 (IL-6)}

In general, IL-6 has pro-inflammatory activity, however in some circumstances it may be modulator and induce anti-inflammatory response. With peripheral nerve injury, IL-6 is released by Schwann cells and macrophages, as well as by neurons and glial cells in DRG and spinal cord. IL-6 predominantly appears in the cascade with TNF and IL-1, however, which comes first is still questionable.

IL-6 role on acute nociceptive pain modulation is contradictory and its peripheral application in animals causes algic and antalgic effects ${ }^{8}$. In laboratory NP models it is obvious the ability of IL-6 to promote pain when rats with genetic deletion of this interleukin are treated with its neutralizing antibody and there is decrease in nervous injury-induced pain.

After nervous injury, IL-6 increases pain responses of mediators such as BDNF and substance $\mathrm{P}$, which promote neuronal excitation.

All cytokine receptors share the same architectural project which involves a large extracellular domain exposed for connection with specific ligant (cykokine) and, united by a single transmembranous helix, an intracellular domain. In case of interleukin-6, response induced by its ligation in the external domain starts with dymerization of receptor which attracts one unit of tyrosine kinase cytosolic (Jak) to associate and then phosphorylate receptor's dymer. Phosphorylation target in the internal domain of IL-6 receptor is a specific protein of the transcription factors family (Stats).

The specific stat is bound to phosphotyrosine grouping of receptor-Jak complex, being itself phosphorylated. Phosphorylated Stat migrates toward cell nucleus and activates genic expression and promotes nervous injury by microglia activation in spinal cord dorsal region.

Analgesic therapeutic possibility arouses from the blockade of this pathway with expected decrease of neuroinflammation diffusion in spinal cord and pain and hypersensitivity attenuation ${ }^{57}$.

In healthy humans, IL-6 levels are very low, but they may increase during painful inflammatory conditions. Antibodies anti-IL-6 (tocilizumab) have been approved for RA and a recent study has shown tocilizumab effectiveness to treat radicular pain and low back pain caused by spinal stenosis ${ }^{58}$. Further clinical trials are needed to evaluate direct effects on NP of IL-6 inhibition.

\section{Other inflammatory cytokines}

Another pleiotropic cytokine, IFN-y, has been associated to chronic pain as from its application. IFN-y may cause neuronal sensitization and trigger spontaneous firings, as well as decreased inhibitory tone. IFN-y is also associated to microglial cells activation, and so IFN-y signalling ablation prevents microglial activation as well as the development of pain and hypersensitivity after nervous injury.

IFN-y signaling with microglia induces over-stimulation of several proteins, such as purinergic receptors $\mathrm{P} 2 \times 4$ and kinase receptor CCR2 $2^{59,60}$ which contribute for NP onset.

Analgesic properties of canabinoid receptor agonists (CBR2) are associ- 
ated to reversible inhibition of microglial cells in activating IFN-y signaling $^{60}$. In general, INF-y are involved with NP pathogenesis, especially by a central effect on neurons and microglia.

IL-15 are expressed in damaged neurons and in macrophage infiltrates of injured nerves, as well as in reciprocity in spinal cord macrophages and reactive microglial cells. These are involved in NP development by promoting macrophages and $\mathrm{T}$ cells at nervous injury side and spinal cord ${ }^{61}$. IL-17 is a pro-inflammatory cytokine predominantly produced by Th17 cells, but also by neutrophils, cytotoxic $\mathrm{T}$ cells and glial cells and has important role in nervous system inflammatory disorders such as multiple sclerosis ${ }^{7,8}$.

IL-17 administration in laboratory rats has induced pain behavior ${ }^{63}$. After nervous injury, IL-17 increases nervous degeneration with peak around the seventh day and is found in $\mathrm{T}$ cells of the injured nerve ${ }^{62}$.

Pain and hypersensitivity are decreased in rats with Rag type 1 defficiency (family of restriction endonuclease enzymes which cleave DNA by recognizing the site by the identification of bases pairs sequences) in $\mathrm{T}$ cells, with failure in Il-17 and IL-17 expression in rats ${ }^{63,64}$. This effect decreases both $\mathrm{T}$ cells and macrophages infiltrate in sciatic nerve decreasing spinal cord glial activity ${ }^{63}$. This way, there are increasing evidences that IL-17 is involved in NP maintenance.

Il-18 is member of IL-1 cytosines family, which are expressed in chronic inflammation and are activated by IL-18 receptors (IL-18r). These are expressed by astrocytes peak seven days after nervous injury. However, neutralizing antibodies against IL-18 and IL-18r only partially decrease pain and hypersensitivity, in spite of the decrease in the number of reactive astrocytes ${ }^{64}$.

A more recent study has shown that herbs used in Japanese medicine (Bushi), have decreased NP maintenance phase by suppressing IL-18 and IL-1b evoked ERK1/2-phosphorylation in astrocytes, thus decreasing their activation ${ }^{61}$. To date, it is still early to state that IL-18 block is a good therapeutic strategy to relieve neuropathic pain and further studies are needed.

\section{ANTI-INFLAMMATORY CYTOKINES}

\section{Interleukin-10}

Interleukin-10, released by activated $\mathrm{T}$ cells, $\mathrm{B}$ cells, macrophages and mast cells, is a powerful anti-inflammatory cytokine, inhibiting cytokines, IL-1b, IL-6 and TNF release ${ }^{6,8}$.

If the catabolic flow is compared to a river flow, substances to be triggered would be at the source while their final metabolites would be at its mouth. In this context, IL-10 suppression mechanisms downstream to its receptor, occur by SOCS3m induction which, in turn, inhibits genes normally activated by JAK-STAT3 pathway, as well as by NF-kB pathway inhibition ${ }^{6,8}$.

After nervous injury, IL-10 expression rapidly increases ( 1 hour) in the injured area and in up to 24 hours in DRG. Spinal and interneuron IL10 may significantly attenuate hypersensitivity of nerve injury-induced pain, associated to decreased infiltration by immune cells and decreased IL-1b and adenosine expression ${ }^{8}$.

Adenosine receptor reverse agonists $2 \mathrm{~A}$ and CBR2 stabilize hypersensitivity pathway of pain induced by IL-10 release ${ }^{66,67}$.

IL-10 has analgesic effects due to its ability to inhibit pro-inflammatory cytokines.

\section{Interleukin-4 (IL-4)}

Interleukin- 4 is a prototypic anti-inflammatory cytokine released by activated mast cells and some T cells populations. It is able to inhibit most inflammatory cytokines and may suppress macrophages and microglial cells activation.

Previous treatment of nerves with IL-4 may desensitize them to responses to painful stimuli induced by knowingly algogenic substances (proinflammatory mediators), such as bradykinins and TNF${ }^{8}$.

IL-4 in knockout rats (-/-) without nervous injuries induces increased sensitivity to mechanical stimulation and, surprisingly, this interleukin in wild rats (with intact genetics) nervous injuries still do not show increased pain hypersensitivity as compared to wild types ${ }^{68}$. This discrepancy seems to be due to the fact that IL- 4 in rats with overcompensation of the expression of other anti-inflammatory cytokines, such as IL-10 and IL-13.

Both nervous injury stabilization and maintenance phases have induced pain hypersensitivity which has been decreased by genes IL- 4 therapy, which is associated to decreased spinal release of IL-1 $\beta$ e PGE2, as well as decreased in p38 MAPK phosphorylated, indicative of decreased number of activated microglial cells ${ }^{69}$. Some IL- 4 analgesic effects also occur by the positive regulation pathway of $\mathrm{med}$ opioids $\mathrm{s}^{6,8}$.

Tumor growth factor-beta (TGF- $\beta$ )

TGF- $\beta$ has a wide variety of immune functions, although being considered an immunosuppressant. TGF- $\beta$ deeply induces lymphocytes proliferation and cytokines production, influences $\mathrm{T}$ cells differentiation and promotes regeneration of $\mathrm{T}$ immunosuppressant-regulating $\mathrm{T}$ cells. After peripheral nerve injury, spinal TGF- $\beta$ significantly attenuates both pain development and maintenance/stabilization ${ }^{69}$. The factor also promotes in these same conditions decreased activation of microglial cells and astrocytes, as well as decreased chemokine CCL2 expression. TGF- $\beta$ and IL-10 may increase blood-spinal cord barrier (BSCB), thus decreasing additional infiltration of immune cells in the dorsal horn. Bone morphogenetic protein and activin membrane-bound inhibitor (BAMBI) are natural inhibitors of the tumor growth factor family. Animals with genetic BAMBI deletion have increased activated TGF- $\beta$ levels and decreased acute pain, as well as NP induced by nervous injury ${ }^{71}$. Antinociceptive TGF- $\beta$ effect may also involve the opioid system since precursor proteins of endogenous opioids have also shown increase in spinal cord of the same mice with deletion of genes responsible for $\mathrm{BAMBI}^{71}$. TGF- $\beta$ seems to activate glial suppression, to inhibit proinflammatory cytokines release and to promote endogenous opioids analgesia expression.

Modulation of these anti-inflammatory cytokines deserves investigation as therapeutic potential for neuropathic pain ${ }^{6}$ and chronic pain in general.

\section{Chemokines}

Chemokines are known as chemo-attractant (or chemo-attractive) cytokines which control leucocytes migration acting as coordinators of cellular traffic during immune and inflammatory reactions. Chemokines and their receptors are important in inflammatory nervous system diseases for mediating leucocytes within nervous inflammation areas.

In fact, there is a slight conflict in naming and classification adopted and already consecrated by custom, since some mediators which are not cytokines also control leucocytes movement and many true cytokines are not restricted to this function.

More than forty chemokines have been identified and their classification may be simplified in two groups, taking into consideration whether primary cystein residues of the polypeptide chain are adjacent (chemokines $\mathrm{C}-\mathrm{C}$ ) or separated by other residue (C-X-C). The former are implied in chronic presentations and the latter in acute presentations.

Major nervous system cell types, such as neurons, glia and neural parent cells, express several chemokines and their receptors.

Evidences gathered on chemokines show involvement of neural migration and cell proliferation during brain development, synaptic transmission modulation, neurodegenerative diseases and pain ${ }^{8}$.

When related to NP, chemokines production leads to higher sensitivity to pain both indirectly by the attraction of leucocytes and indirectly by nociceptive neurons excitation.

Chemokines and their receptors were implied in NP. Two most important pairs (ligant + receptor) are commented below.

\section{CCL2 (MCP-1)/CCR2}

The expression of CCL2 cytokine and its respective receptor (CCR2) on neurons and glial cells in DRG is already well documented ${ }^{8,72}$. Using an NP model of chronic DRG compression, it was shown increased CCR2 and CCL2 expression both in injured and healthy (without compression) neurons. The application of CCL2 in injured sensory nerves in vivo produces potent excitatory effects ${ }^{73}$. After sciatic nerve injury, similar findings of increased expressison of CCL2 in DRG neurons and within endoneuron are evident ${ }^{74}$.

However, CCL2/CCR2 expression in spinal cord is controversial. Several evidence lines show that CCR 2 constitutively occurs in spinal cord 
neurons and become hyperactive after nervous injury ${ }^{75}$.

CCL2/CCR2 signaling in spinal cord is a critical point for the activation of spinal glia, and there is possibility of this chemokine produced in DRG to be transported to proximal terminations of such pseudo-unipolar neurons in gray matter dorsal portion. Inthratecal administration of CCL2 neutralizing antibodies in animals with nervous injury has shown decreased microglia activation and pain behavior inhibition ${ }^{76}$.

Confirming such findings, rats without CCR2 have shown little NP after nervous injury, resulting from decreased macrophages infiltration, spinal glia cells activation and decreased neuronal sensitization ${ }^{77}$. CCR2 activation on DRG neurons and CCL2 release in spinal cord nervous system contribute to increased nociceptive neurons excitation and NP promotion. CCR2 antagonists may have therapeutic value in the future ${ }^{6,78,79}$

\section{CX3CL1 (fractalkine)/CX3CR1}

Fractalkine is a cytokine expressed in the external surface of spinal neuron cells and of spinal cord sensory afferents ${ }^{80}$. In spinal cord dorsal part, fractalkine receptors are primarily expressed by microglia and are over-functioning after nervous injury ${ }^{81}$

CX3CL1/CX3CR1 expression pattern suggests their involvement in neuronal signaling and spinal cord microglia.

Binding of CX3CL1 and CX3CR1 activates P38 MAPK inducing microglial activation and pro-inflammatory cytokines synthesis, such as TNF, IL- $1 \mathrm{~b}$ and IL- $6^{75}$. This, in turn, contributes to synapses plasticity and spinal cord neuronal activation.

Behavioral studies have shown that spinal fractalkine produces dose-dependent pain and hypersensitivity, while neutralizing CX3CR1 antibodies injection delays and decreases nociceptive response in NP models $s^{82}$.

CX3CR1 blockade in rats decreases pain and hypersensitivity with decreased spinal glial activation after peripheral nervous injury ${ }^{83}$. Evidences suggest that fractalkine (CX3CL1) release by neurons in response to injury or to an inflammatory mediator induces glial activation and pain facilitation.

\section{CONCLUSION}

There is increasing production of evidences obtained by pre-clinical trials showing that inflammatory mediators play critical roles in NP pathogenesis.

In peripheral nervous system, inflammatory mediators are hyper-regulated by resident cells and infiltrate leucocytes after peripheral nerve injury, inducing peripheral sensitization. In central nervous system, in spinal cord, inflammatory mediators broadly contribute to glial cells activation after nervous injury, inducing central sensitization.

Modulation and intensional direction of these mediators inhibiting proinflammation and increasing anti-inflammatory mediators, may be considered important therapeutic strategies for NP. However, recent scientific production also cautions for the difficulty to translate results obtained in this animal research field into application in humans.

\section{REFERENCES}

1. Rahmati M, Mobasheri A, Mozafari M. Inflammatory mediators in osteoarthritis: A critical review of the state-of-the art, current prospects, and future challenges. Bone. 2016;81-90.

2. Oliveira Jr JO. Aspectos referentes à fisiopatologia comparada entre dor neuropática e espasticidade. Rev Dor. 2000;2(1):30.

3. Dawes JM, Anderson DA, Bennett DL, Bevan S, McMahon SB. Inflammatory mediators and modulators of pain. Wall and Melzack's Textbook of Pain. 2013;6:48-67.

4. Oliveira Jr JO. A cronificaçáo da dor. O papel dos analgésicos anti-inflamatórios como os inibidores da ciclo-oxigenase do tipo 2 e dos anticonvulsivantes como os gabapentinóides na transiçáo da dor aguda para crônica. Revisão clínica. Discutindo a dor. 2014;71-7.

5. Kawahara K, Hohjoh H, Inazumi T, Tsuchiya S, Sugimoto Y. Prostaglandin E2-induced inflammation: Relevance of prostaglandin E receptors. Biochim Biophys Acta. 2015;1851(4):414-21.

6. Austin PJ, Moalem-Taylor G. Pathophysiology of neuropathic pain: inflammatory mediators. In Toth C, Moulin DE, (editors). Neuropathic Pain. Cambridge University Press: New York; 2013;(7):77-89p.

7. Moalem G, Tracey DJ. Immune and inflammatory mechanisms in neuropathic pain. Brain Res Rev. 2006;51(2):240-64

8. Austin PJ, Moalem-Taylor G. The neuro-immune balance in neuropathic pain: involvement of inflammatory immune cells, immune-like glial cells and cytokines. J Neuroimmunol. 2010;229(12):26-50.

9. Talbot S, Théberge-Turmel P, Liazoghli D, Sénécal J, Gaudreau P, Couture R. Cellular localization of kinin B1 receptor in the spinal cord of strepzotocin-diabetic rats with a fluorescent (Nalpha-Bodipy)-des-Arg9-bradykinin. J Neuroinflammation. 2009;6:11.

10. Rashid $\mathrm{MH}$, Inoue M, Matsumoto M, Ueda H. Switchng of bradykinin-mediated nociception following partial sciatic nerve injury in mice. J Pharmacol Exp Ther. 2004;308(3):1158-64.

11. Wang H, Kohno T, Amaya F, Brenner GJ, Ito N, Allchorne A, et al. Bradykinin produces pain hypersensitivity by potentiating spinal cord glutamatergic synaptic transmission. J Neusci. 2005;25(35):7986-92.

12. Wener MF, Kassuya CA, Ferreira J, Zampronio AR, Calixto JB, Rae GA. Peripheral kinin B(1) and $\mathrm{B}(2)$ receptor-operated mechanisms are implicated in neutopathic nociceotion induce by spinal nerve ligation in rats. Neuropharmacology. 2007;53(1):48-57.

13. Luiz AP, Schroeder SD, Chichorro JG, Calixto JB, Zampronio AR, Rae GA. Kinin B(1) and B(2) receptors contribute to orofacial heat hyperalgesia induced by infraorbital nerve constriction injury in mice and rats. Neuropeptides. 2010;44(2):87-92.

14. Ferreira J, Beirith A, Mori MA, Araújo RC, Bader M, Pesquero JB, et al, Reduced nerve injury-induced neuropathic pain in kinin B1 receptor knock-out mice. J Neurosci. 2005;25(9):2405-12.

15. Moalem G, Grafe P, Tracey DJ. Chemical mediators enhance the excitability of unmyelinated sensory axons in normal and injured peripheral nerve of the rat. Neuroscience. 2005;134(4):1399-411. Keppel Hesselink JM. The terms 'autacoid', 'hormone' and 'chalone' and how they have shifted with time. Auton Autacoid Pharmacol. 2016; [Epub ahead of print).

17. Gu JG, MacDermott AB. Activation of ATP P2X receptors elicits glutamate realese from sensory neuron synapses. Nature. 1997:389(6652):749-53.

18. Hide I, Tanaka M, Inoure A, Nakajima K, Kohsaka S, Inoue K, et al. Extracellular ATP trigger tumor necrosis factor-alpha release from rat microglia. J Neurochem. 2000;75(3):965-72.

19. Tsuda M, Shigemoto-Mogami Y, Koizumi S, Mizokoshi A, Kohsaka S, Salter MW, et al P2X4 receptors induced in spinal microglia gate tactile allodynia after nerve injury. Nature. 2003; $424(6950): 778-83$

20. Trang T, Beggs S, Salter MW. ATP receptors gate microglia signaling in neuropathic pain. Esp Neurol. 2012;234(2):354-61.

21. Honore P, Donnelly-Roberts D, Namovic M, Chong C, Wade C, Chandran P, et al. The antihyperalgesic activity of a selective P2X7 receptor antagonist, A-839977, is lost in IL-1alphabeta knockout mice. Behav Brain Res. 2009;204(1):77-81.

22. Chessell IP, Hatcher JP, Bountra C, Michel AD, Hughes JP, Green P, et al. Disruption of the P2X purineceptor gene abolishes chronic inflammatory and neuropathic pain. Pain. 2005;114(3):386-96

23. Sorge RE, Trang T, Dorfman R, Smith SB, Beggs S, Ritchie J, et al. Genetically determined P2X receptor pore formation regulates variability in chronic pain sensitivity. Nat Med. 2012;18(4):595-9

24. Maeda M, Tsuda M, Tozaki-Saitoh H, Inoue K, Kiyama H. Nerve injury-activated microglia engulf myelinated axons in a P2Y12 signaling-dependent manner in the dorsal horn. Glia. 2010:58(15):1838-46.

25. Tozaki-Saitoh H, Tsuda M, Miyata H, Ueda K, Kohsaka S, Inoue K. P2Y12 receptors in spinal microglia are required for neuropathic pain after peripheral nerve injury. J Neurosci. 2008;28(19):4949-56. Ma W, Chabot JG, Vercauteren F, Quiron R. Injured nerve-derived COX2/PGE2 contributes to the maintenance of neuropathic pain in aged rats. Neurobiol Aging. 2010;31(7):1227-37.

27. Naidu RK, Pham TM. Pain Management. In Basic Clinical Anesthesia. New York: Springer; 2015. 265-96p.

28. Namaka M, Gramlich CR, Ruhlen D, Melanson M, Sutton I, Major J. A treatment algorithm for neuropathic pain. Clin Ther. 2004;26(7):951-79.

29. Jain NK, Kulkarni SK, Singh A. Role of cysteinyl leukotrienes in nociceptive and inflammatory conditions un experimental animals. Eur J Pharmacolol. 2001;423(1):85-92.

30. Okubo M, Yamada H, Kobayshi K, Noguchi K. Leuckotriene synthases and the receptors induced by peripheral nerve injury in the spinal cord contribute to the generation of neuropathic pain. Glia. 2010;58(5):599-610.

31. Zuo Y, Perkins NM, Tracey DJ, Geczy CL. Inflammation and hyperalgesia induced by nerve injury in the rat: a key role of mast cells. Pain. 2003;105(3):467-79.

32. Cannon KE, Leurs R, Houng LB. Activation of peripheral and spinal histamine H3 receptors inhibits formalin-induced inflammation and nociception, respectively. Pharmacol Biocherm Behav. 2007;88(1):122-9.

33. Sanna MD, Stark H, Lucarini L, Ghelardini C, Masini E, Galeotti, N. Histamine H4 recepto activation alleviates neuropathic pain through differential regulation of ERK, JNK, and P38 MAPK phosphorylation. Pain. 2015;156(12):2492-504

34. Ossipov MH. Growth factors and neuropathic pain. Curr Pain Headache Rep. 2011;15(3):185-92

35. Petty BG, Cornblath DR, Adornato BT, Claeudhry V, Flexner C, Wachsman M, et al. The effect of systemically administered recombinant human nerve growth factor in healthy human subjects. Ann Neurol. 1994;36(2):244-6.

36. Wild KD, Bian D, Zhu D, Davis J, Bannon AW, Zhang TJ, et al. Antibodies to nerve growth facto reserve established tactile allodynia in rodent models of neuropathic pain without tolerance. J Pharmacol Exp Ther. 2007;322(1):282-7.

37. Katz N, Borenstein DG, Birbara C, Bramson C, Nemeth MA, Smith MD, et al. Efficacy and safety of tanezumab in the chronic low back pain. Pain. 2011;152(10):2248-58.

38. Hill R. Blocking the effects of NGF as a route to safe and effective pain relief--fact or fancy? Pain. 2011;152(10):2200-1. Autor replay in Pain. 2012:153:1128-9.

39. Coull JA, Beggs S, Boudreau D, Boivin D, Tsuda M, Inoue K, et al. BDNF from microglia causes the shift in neuronal anion gradient underlying neuropathic pain. Nature. 2005;438(7070):1017-21.

40. Mrozkova P, Palecek J, Spicarova D. The role of protease-activated receptor type 2 in nociceptive signaling and pain. Physiol Res. 2016. [Epub ahead of print].

41. Balkowiec-Iskra E, Vermehren-Schmaedick A, Balkowiec A. Tumor necrosis fator- $\alpha$ increases brain-derived neuropathic factor expression in trigeminal ganglion neurons in an activity-dependent manner. Neuroscience. 2011;180:322-33.

42. Adler JE, Nico L, VandeVord P, Skoff AM. Modulation of neuropathic pain by a glial-derived factor Pain Med. 2009;10(7):1229-36.

43. Guo J, Jia D, Jin B, Xu F, Yuan X, Shen H. Effects of glial cell line-derived neuropathic factor intrathecal injection on spinal dorsal horn glial fibrillary acidic protein expression in a rat model of neuropathic pain. Int J Neurosci. 2012;122(7):388-94.

44. Maseda D, Johnson E, Crofford L. Production of inflammatory cytokines is regulated by mPGES-1-Dependent PGE2 in T cells. Inflammatory Bowel Dis. 2016;22:S49:130.

45. Oliveira Jr JO, Amorim Filho BD. The integrins and the painfull phenomenum. Rev Dor 2006; $7(1) 710-5$

46. Echeverry S, Shi XQ, Rivest S, Zhang J. Peripheral nerve injury alters blood-spinal cord barrier functional and molecular integrity trhough a selective inflammatory pathway. J Neurosci. 2011;31(30):10819-28.

47. Wei XH, Zang Y, Wu CY, Xu JT, Xin WJ, Liu XG. Peri-sciatic administration of recombinant rat TNF-alpha induces mechanical allodynia via upregulation of TNF-alpha in dorsal root ganglia and in spinal dorsal horn: the role of NF-kappa B pathway. Exp Neurol. 2007;205(2):471-84.

48. Junger H, Sorkin LS. Nociceptive and inflammatory effects of subcutaneous TNFalpha. Pain. 2000;85(1-2):145-51

49. Kawasaki Y, Zhang I, Cheng JK, Ji RR. Cytikine mechanisms of central sensitization: distinct and overlapping role of Interleukin-1beta, Interleukin-6 and tumor necrosis factor alpha in regulating 
synaptic and neuronal activity in the superficial spinal cord. J Neurosci. 2008;28(20):5189-94.

50. Schaible HG, von Banchet GS, Boettger MK, Brauer R, Gajda M, Richter F, et al. The role of proinflammatory cytokines in the generation and maintenance of joint pain. Ann N Y Acad Sci. 2010;1193:60-9.

51. Sommer C, Schaferns M, Marziniak M, Toyka KV. Etanercept reduces hyperalgesia in experimental painful neuropathy. J Peripher Nerv Syst. 2001;6(2):67-72.

52. Korhonen T, Karppinen J, Paimela L, Malmivaara A, Lindgren KA, Bowman C, et al. The treatment of disc-herniation-induced sciatica with infliximab: one-year follow-up results of FIRST II, a randomized controlled trial. Spine. 2006;31(24):2759-66.

53. Whitehead KJ, Smith CG, Delaney SA, Curnow SJ, Salmon M, Hughes JP, et al. Dynamic regulation of spinal pro-inflammatory cytokine release in rat in vivo following peripheral nerve injury. Brain Behav Immun. 2010;24(4):569-76.

54. Nadeau S, Filali M, Zhang J, Kerr BJ, Rivest S, Soulet D, et al. Functional recovery after peripheral nerve injury is dependent on the pro-inflammatory cytokines IL-1 $\beta$ and TNF: implications for neuropathic pain. J Neurosci. 2011;31(35):12533-42.

55. Murphy PG, Ramer MS, Borthwick L, Gauldie J, Richardson PM, Bisby MA. Endogenous interleukin-6 contributes to hypersensitivity to cutaneous stimuli and changes in neuropeptides associated with chronic nerve constriction in mice. Eur J Neurosci. 1999;11(7):2243-53.

56. Kiguchi N, Maeda T, Kobayashi Y, Kondo T, Ozaki M, Kishioka S. The critical role of invading peripheral macrophage-derived interleukin-6 in vincristine-induced mechanical allodynia in mice. Eur J Pharmacol. 2008;592(1-3):87-92.

57. Dominguez E, Mauborgne A, Mallet J, Desclaux M, Pohl M. SOCS3-mediated blockade of JAK/ STAT3 signaling pathway reveals its major contribution to spinal cord neuroinflammation and mechanical allodynia after peripheral nerve injury. J Neurosci. 2010;30(16):5754-66.

58. Ohtori S, Miyagi M, Eguchi Y, Inoue G, Orita S, Ochiai N, et al. Efficacy of epidural administration of anti-interleukin-6 receptor antibody onto spinal nerve for treatment of sciatica. Eur Spine J. 2012;21(10):2079-84

59. Tsuda M, Masuda T, Kitano J, Shimoyama H, Tozaki-Saitoh H, Inoue K. IFN-gamma receptor signaling mediates spinal microglia activation driving neuropathic pain. Proc Natl Acad Sci USA. 2009; 106(19):8032-7.

60. Racz I, Nadal X, Alferink J, Baños JE, Rehnelt J, Martín M, et al. Interferon-gamma is a critical modulator of $\mathrm{CB}(2)$ cannabinoid receptor signaling during neuropathic pain. J Neurosci. 2008;28(46):12136-45.

61. Gómez-Nicola D, Valle-Argos B, Suardiaz M, Taylor JS, Nieto-Sampedro M. Role of IL-15 in spinal cord and sciatic nerve after chronic constriction injury: regulation of macrophage and T-cell infiltration. J Neurochem. 2008;107(6):1741-52.

62. Kleinschnitz C, Hofstetter HH, Meuth SG, Braeuninger S, Sommer C, Stoll G. T cell infiltration after chronic constriction injury of mouse sciatic nerve is associated with interleukin-17 expression. Exp Neurol. 2006;200(2):480-5

63. Kim CF, Moalem-Taylor G. Interleukin-17 contributes to neuroinflammation and neuropathic pain following peripheral nerve injury in mice. J Pain. 2011;12(3):370-83.

64. Miyoshi K, Obata K, Kondo T, Okamura H, Noguchi K. Interleukin-18-mediated microglia/astrocyte interaction in the spinal cord enhances neuropathic pain processing after nerve injury. J Neurosci. 2008;28(48):12775-87.

65. Shibata K, Sugawara T, Fujishita K, Shinozaki Y, Matsukawa T, Suzuki T, et al. The astrocyte-targeted therapy by Bushi for the neuropathic pain in mice. PLoS One. 2011;6(8):e23510.

66. Loram LC, Harrison JA, Sloane EM, Hutchinson MR, Sholar P, Taylor FR, et al. Enduring reversal of neuropathic pain by a single intrathecal injection of adenosine $2 \mathrm{~A}$ receptor agonists: a novel therapy for neuropathic pain. J Neurosci. 2009;29(44):14015-25.

67. Wilkerson JL, Gentry KR, Dengler EC, Wallace JA, Kerwin AA, Armijo LM, et al. Intrathecal cannabilactone $\mathrm{CB}(2) \mathrm{R}$ agonist, $\mathrm{AM} 1710$, controls pathological pain and restores basal cytokine levels. Pain. 2012;153(5):1091-106.

68. Üceyler N, Topuzoglu T, Schiesser P, Hahnenkamp S, Sommer C. IL-4 deficiency is associated with mechanical hypersensitivity in mice. PLoS One 2011;6(12):e28205.

69. Hao S, Mata M, Glorioso JC, Fink DJ. HSV-mediated expression of interleukin-4 in dorsal root ganglion root ganglion neurons reduces neuropathic pain. Mol Pain. 2006;2:6.

70. Echeverry S, Shi XQ, Haw A, Liu H, Zhang ZW, Zhang J. Transforming growth factor-beta impairs neuropathic pain through pleiotropic effects. Mol Pain. 2009;5:16.

71. Tramullas M, Lantero A, Díaz A, Morchón N, Merino D, Villar A, et al. BAMBI (bone morphogenetic protein and activin membrane-bound inhibitor) reveals the involvement of the transforming growth factor-beta family in pain modulation. J Neurosci. 2010;30(4):1502-11.

72. Gao YJ, Ji RR. Chemokines, neuronal-glial interactions, and central processing of neuropathic pain. Pharmacol Ther. 2010;126(1):56-68.

73. White FA, Sun J, Waters SM, Ma C, Ren D, Ripsch M, et al. Excitatory monocyte chemoattractant protein-1 signaling is up-regulated in sensory neurons after chronic compression of the dorsal root ganglion. Proc Natl Acad Sci USA. 2005;102(39):14092-7.

74. Tanaka T, Minami M, Nakagawa T, Satoh M. Enhanced production of monocyte chemoattractan protein-1 in the dorsal root ganglia in a rat model of neuropathic pain: possible involvement in the development of neuropathic pain. Neurosci Res. 2004;48(4):463-9.

75. Gao YJ, Zhang L, Samad OA, Suter MR, Yasuhiko K, Xu ZZ, et al. JNK-induced MCP-1 production in spinal cord astrocytes contributes to central sensitization and neuropathic pain. J Neurosci. 2009;29(13):4096-108

76. Thacker MA, Clark AK, Bishop T, Grist J, Yip PK, Moon LD, et al. CCL2 is a key mediator of microglia activation in neuropathic pain states. Eur J Pain. 2009;13(3):263-72.

77. Abbadie C, Lindia JA, Cumiskey AM, Peterson LB, Mudgett JS, Bayne EK, et al. Impaired neuropathic pain responses in mice lacking the chemokine receptor CCR2. Proc Natl Acad Sci USA. 2003;100(13):7947-52.

78. Old EA, Nicol LS, Malcangio M. Recent advances in neuroimmune interactions in neuropathic pain: the role of microglia. An Introduction to Pain and its relation to Nervous System Disorders. 2016;123T. http://onlinelibrary.wiley.com/doi/10.1002/9781118455968.ch4/summary

79. Thakur M, McMahon SB. Symptoms and pathology in neuropathic pain. An introduction to pain and its relation to nervous system disorders, 2016;89-121. http://onlinelibrary.wiley.com/ doi/10.1002/9781118455968.ch3/summary

80. Verge GM, Milligan ED, Maier SF, Watkins LR, Naeve GS, Foster AC. Fractalkine (CX3CL1) and fractalkine receptor $\left(\mathrm{CX}_{3} \mathrm{CR} 1\right)$ distribution in spinal cord and dorsal root ganglia under basal and neuropathic pain conditions. Eur J Neurosci. 2004;20(5):1150-60.

81. Lindia JA, McGowan E, Jochnowitz N, Abbadie C. Induction of CX3CL1 expression in astrocytes and CX3CR1 in microglia in the spinal Cord of a rat modelo f neuropathic pain. J Pain 2005;6(7):434-8.

82. Milligan ED, Zapata V, Chacur M, Schoeniger D, Biedenkapp J, O'Connor KA, et al. Evidence that exogenous and endogenous fractalkine can induce spinal nociceptive facilitation in rats. Eur J Neurosci. 2004;20(9):2294-302

83. Staniland AA, Clark AK, Wodarski R, Sasso O, Maione F, D'Acquisto F, et al. Reduced inflammatory and neuropathic pain and decreased spinal microglial response in fractalkine receptor (CX3CR1) knockout mice. J Neurochem. 2010;114(4):1143-57. 